\title{
A morte em Morte e Vida Severina: estudo sobre a dimensão trágica do texto de João Cabral de Melo Neto
}

\author{
Death in Morte e Vida Severina: \\ a study on the tragic dimension of \\ João Cabral de Melo Neto's drama
}

Felipe Gonçalves Figueira ${ }^{1}$

\begin{abstract}
Resumo: O presente estudo busca relacionar a ideia da morte severina com a experiência da tragédia grega. A análise comparada evidencia as dimensões trágicas desse texto de João Cabral de Melo Neto. Para tanto, são importantes as proposições metodológicas fundadas no pensamento dialógico de Mikhail Bakhtin (2008, 2015). São relevantes, também, os estudos de Vernant e Vidal-Naquet (2008) sobre a tragédia.
\end{abstract}

Palavras-chave: Tragédia. Morte e Vida Severina. João Cabral de Melo Neto.

Abstract: This study seeks to relate the idea of "severina's" death with the experience of the Greek tragedy. The comparative analysis shows the tragic dimensions of this drama by João Cabral de Melo Neto. For this, methodological propositions based on the dialogical thinking of Mikhail Bakhtin (2008, 2015) are important. Also relevant are the studies by Vernant and Vidal-Naquet (2008) on Tragedy.

Keywords: Tragedy. Morte e Vida Severina. João Cabral de Melo Neto.

João Cabral de Melo Neto talvez seja mais conhecido do grande

Professor de Ensino e Tecnologia do Instituto Federal Fluminense 
público por sua obra dramática do que lírica. Publicado pela primeira vez em 1955, o texto de Morte e vida severina, auto de Natal pernambucano já recebeu muitas montagens teatrais - como a famosa encenação no Teatro da Universidade Católica de São Paulo (Tuca) em 1965, com músicas de Chico Buarque de Holanda e direção de Silnei Siqueira e Roberto Freire (TEATRO TUCA, 10/ 09/2019) - e, até mesmo, uma adaptação televisiva de 1981, com direção de Walter Avancini e atuações de Tânia Alves e José Dumont (MEMÓRIA GLOBO, 10/ 09/2019). Ao receber Melo Neto na Academia Brasileira de Letras, José Américo de Almeida, em referência a esse texto, aponta que na realização dessa obra o autor "é o poeta do coletivo e passa a ser mais ouvido. Acolhe o palco a poesia viril dandolhe maior audiência." (ALMEIDA, 10/09/2019). O que o autor paraibano aponta sobre o texto de Melo Neto em análise é justamente a pujança à recepção popular, sua capacidade de produzir sentidos para o grande público.

No entanto, certamente se enganará quem concluir que Morte e vida severina é um texto de menor complexidade estética no conjunto da obra de Melo Neto. Para provar essa afirmação, não preciso ir demasiadamente longe. O título do texto lido e relido - muitas vezes sem a devida atenção - já aponta para determinadas complexidades de forma e de conteúdo presentes na materialização da obra. Antecedendo a morte à vida, o título aponta para algo que seria antinatural, ilógico e impossível. No entanto, é uma chave de leitura oferecida pelo próprio autor para a compreensão de sua obra.

O caminho que o retirante percorre até o Recife é marcado pelos encontros com a morte que ele mesmo já havia enumerado no seu primeiro diálogo com o leitor:

E se somos Severinos iguais em tudo na vida, morremos de morte igual, 
mesma morte severina:

que é a morte de que se morre

de velhice antes dos trinta,

de emboscada antes dos vinte,

de fome um pouco por dia

(de fraqueza e de doença

é que a morte severina

ataca em qualquer idade,

e até gente não nascida).

(MELO NETO, 1983, p. 71)

Durante a migração, o retirante se depara com essas espécies de morte severina. Conclui a jornada com a escuta da conversa dos dois coveiros no Recife. A partir dessa escuta, pode unir todos os pedaços do quebra-cabeça espalhados pelo caminho e concluir que não é o local que define a condição severina, mas um estado de coisas na sociedade de todo o lugar, que hierarquiza e aliena os homens.

Sobre a apresentação que pretendo desenvolver nas próximas páginas, Benedito Nunes (2007, p. 61). já apontara que o nascimento do menino cinde a obra em duas: morte versus vida. Teríamos, assim, no segundo fluxo, aquele relativo à vida, um "auto dentro do auto". O filósofo paraense analisa que

É fácil perceber, por essa diferença de ritmo, a composição mista do drama, que se perfaz em dois movimentos simétricos, nos limites da oposição entre morte e vida compreendida pelo próprio título do Auto: o da viagem de Severino até o Recife, pesado e sombrio, que corresponde à morte; o do outro auto natalino, leve e alegre, que corresponde à vida. A cada um desses movimentos ou partes pertence um dado tipo de temporalidade. O da primeira é o tempo como desgaste dos seres e das coisas, um tempo destrutivo e não cumulativo, que não se dá como aproximação natural à morte e sim como antecipação 
dela. (NUNES, 2007, p. 62)

Nessa proposição de análise, morte severina corresponde a todo o caminho feito pelo retirante, que vai desde sua cidade acossada pela miséria até sua chegada a Recife - onde escuta a conversa de dois coveiros e decide pular da ponte sobre o rio Capibaribe. $\mathrm{O}$ auto pastoril é um gênero artístico da cultura popular brasileira que deita suas raízes na tradição ibérica. Sintetiza Hermilo Borba Filho $(2007,115)$ que o "pastoril era, a princípio, a representação do drama hierárquico do Nascimento de Jesus Cristo, com bailados e cantos próprios. 'Aproximava-se o Natal, entrava em cena o pastoril'.”. A retomada da esperança na vida severina está intimamente ligada ao despontar da expressão do gênero artístico popular no texto de Melo Neto.

Em busca de paralelismo analítico, a atenção do estudioso da literatura é facilmente tomada pela tentativa de compreensão do primeiro fluxo da obra - aquele relativo à morte - também em termos de gêneros literários. A morte anunciada em cada parada, o destino do qual Severino se aproxima na tentativa de distanciar-se: são elementos trágicos relidos a partir de referências econômicas e culturais do Brasil do século XX. É ainda Benedito Nunes que nos aponta para o fato de que

[...] podemos subir ainda mais nessa escala temática até alcançarmos o nível da possibilidade trágica em que o ser severino parecia confundir-se com a vítima de um destino cego e fatal, produto de forças adversas e incontroláveis, não fosse a paragem e o desvio da ação, permitidos pela estrutura do drama, que é, ao mesmo tempo, bivalente, mista, didática e aberta. (NUNES, 2007, p. 61. Grifos no original)

A possibilidade trágica de que nos fala Nunes é aquela irrealizada, suspensa pelo acontecimento da festa popular no instante que antecederia 
o momento fatídico, pela celebração da vida do menino nascido nos mangues do Recife, pelo "auto de Natal dentro do auto de Natal”. É a vida festiva do pastoril popular que suspende a marcha da morte trágica.

Como se conclui desses apontamentos iniciais, embora Morte e vida severina seja a obra de maior reconhecimento na obra de Melo Neto, essa peça não pode ser considerada como realização menor. Ao contrário, ao estabelecer diálogo com a tradição do gênero trágico e relacionar-se - em contrapasso estético - ao auto popular em seus signos e formas, e, ainda assim, permanecer acessível à compreensão de grande gama de espectadores e leitores, fugindo de academicismo ou de posturas pretensamente intelectualizadas, Melo Neto demonstra a maestria na realização dessa obra.

Para o presente artigo, retomo a proposição apresentada por Benedito Nunes (2007) e debruço-me sobre a dimensão trágica presente em Morte e vida severina. O trágico, nesse sentido específico, não se confunde com aquele mesmo da Grécia antiga. Busco evidenciar que sob novas circunstâncias enunciativas - há dimensões trágicas ainda pertinentes na memória coletiva. Para tanto, valho-me metodologicamente das proposições de Mikhail Bakhtin $(2008,2015)$ sobre dialogismo. Buscando compreender melhor o gênero clássico da tragédia, recorro a Vernant e Vidal-Naquet em Mito e tragédia na Grécia antiga (2008).

\section{Textos e seus contextos}

O surgimento da tragédia grega se dá em um período muito específico da história, em que se operavam naquela sociedade grega modificações de suas estruturas. A edificação de novas instituições na cultura grega gerou consequências irreparáveis na percepção de mundo. O universo espiritual da religião, outrora único domínio norteador do agir, concorre com uma nova instituição social cujas orientações incidem também no 
comportamento humano. A contemporaneidade de dois discursos que recaiam sobre a consciência do homem é uma das condições essenciais para o surgimento da tragédia grega. Jean-Pierre Vernant definiu que nessa época

[...] também com a cidade, desenvolve-se um sistema de instituições e de comportamentos, um pensamento propriamente político. Ainda aí é nítido o contraste com as antigas formas míticas de poder e de ação social que a pólis substituiu juntamente com as práticas e a mentalidade que lhes eram solidárias. (VERNANT; VIDAL-NAQUET, 2008, p. 9).

É nesse rápido momento de transição, que não durou mais que dois séculos, que se deu a ascensão e consolidação do gênero trágico. O homem trágico é caracterizado pela sua consciência em estado limítrofe entre as velhas formas míticas de ser e estar no mundo e aquelas ditadas pelo desenvolvimento da pólis, em especial o discurso jurídico. Na tragédia, debatem-se valores do passado e contingências atualizadas daquele grupo social. A concorrência entre o discurso mítico e o jurídico é tão intensa que se dá inclusive no plano semântico das palavras. Em As Suplicantes, por exemplo, a mesma palavra para o rei Pelasgo e para as Danaides possuía significados diferentes:

Na boca do rei Pelasgo, krátos, associado a kýrios, designa uma autoridade legítima, o domínio que, com pleno direito, o tutor exerce sobre quem juridicamente depende de seu poder; na boca das Danaides, a mesma palavra, atraída pelo campo semântico de bia, designa a força brutal, a coerção da violência no seu aspecto mais oposto à justiça e ao direito. (VERNANT; VIDAL-NAQUET, 2008, p. 16) 
A indefinição semântica ocorre também na obra de Melo Neto. A ação gira em torno dos conceitos da morte e da vida severina. A caracterização da morte é construída pelo retirante Severino com a vida que se extingue "de velhice antes dos trinta", "de emboscada antes dos vinte" e "fraqueza e doença todo dia". A vida é apresentada a todo o momento como um inexorável caminho para a morte. Essa proposição discursiva é confirmada em ação dramática pelas cenas dos encontros que o retirante Severino trava no caminho a Recife. Há um jogo cambiante entre os sentidos de morte e de vida, que se anulam na condição severina, perdendo a distinção fática e semântica. A vida severina é justamente o campo em que se alimenta com fartura a morte.

\section{Ação humana e destino}

A fórmula trágica está na oposição do êthos do sujeito e do daímon de uma potência superior que contra ele se abate. Vernant (VERNANT; VIDAL-NAQUET, 2008, p. 47). conceitua caráter, ou êthos, como uma característica própria de cada gênero de homem e tem como base a soma de disposições (héxeis) que se desenvolvem pela prática e se fixam em hábitos. Uma vez formado o caráter, o sujeito age de acordo com essas disposições e não poderia fazer de outra forma.

$\mathrm{Na}$ experiência trágica grega, abate-se contra o homem um futuro que lhe excede em forças, lançando suas sombras sobre seu destino. Constituem-se, assim, duas realidades. Uma delas terrena, da afirmação do homem, e outra ditada por potências que vão além de suas forças, de seu querer. Segundo Vernant (2008, p. 14), o problema da tragédia está em sabermos se o ato é feito por vontade individual ou por acontecimento inelutavelmente condicionado pelo destino. "Em grego, um termo designa esse tipo de potência divina, pouco individualizada, que, sob uma 
variedade de formas age de uma maneira que, no mais das vezes, é nefasta ao coração da vida humana: o daimon." (VERNANT; VIDAL-NAQUET, 2008, p. 14). Daímon é lido também como um gênio mau que se apossa do espírito do homem. Vernant e Naquet (2008, p. 28) assim parafraseiam a proposição de Lesky:

O herói confronta-se com uma necessidade superior que se impõe a ele, que o dirige, mas para um movimento próprio de seu caráter, ele apropria-se desta necessidade e torna-a seu querer, até desejar apaixonadamente aquilo que, num outro sentido, é constrangido a fazer.

É a busca por superar a condição severina que transforma um "severino comum" no retirante Severino, "herói" do auto de Natal pernambucano. É essa necessidade superior com a qual se confronta que impulsiona seu movimento em direção a Recife. Este é o caráter do "herói”: a busca pela sobrevivência, pela "água pouca, dentro da cuia, a farinha, o algodãozinho da camisa, ou (meu) aluguel com a vida" (MELO NETO, 1983, p. 99). Chegando a seu destino, um discurso opressor - proveniente da boca dos coveiros - se insere na consciência do retirante Severino, transformando-se em seu querer: "A solução é apressar a morte a que se decida" (MELO NETO, 1983, p. 101). Lugar ocupado anteriormente pelo desejo de vida é agora apossado pelo desejo de morte. Trata-se da compreensão do retirante sobre seu destino severino: a morte severina inescusável ao agir do personagem. Neste sentido, apontam os pensadores franceses:

A todo o momento, a vida do herói se desenrola como que sobre dois planos, cada um dos quais, tomado em si mesmo, seria suficiente para explicar as peripécias do drama, mas que a tragédia precisamente visa 
apresentar como inseparáveis um do outro: cada ação aparece na linha e na lógica de um caráter, de um êthos, no próprio momento que ele se revela como manifestação de uma potência do além, de um daímon. (VERNANT; VIDAL-NAQUET, 2008, p.15)

A estrutura da obra grega pressupõe uma "potência superior", cujas forças têm capacidade de influir na vida do homem social. Modernamente se faz, assim, impossível um teatro reproduzir essa estrutura neste nível, pois a exigência está ligada às condições de produção do discurso grego trágico, do surgimento da pólis e da reorganização epistemológica gerada na compreensão de mundo do homem grego: com a consciência reorientada entre o discurso mítico, politeísta e inalcançável do passado e o discurso novo, do homo politicus.

Subsistem, de outra forma, na segunda metade do século XX, discursos que propõem verdadeiras "potências do além", cujas ações humanas individuais têm pouco impacto de alteração. Adam Smith (1996) em A Riqueza das nações propõe a tal "mão invisível da economia", ente capaz de gerar empregos, retirá-los de um lugar e transportá-los para outro de acordo com "sua conveniência". São ordinárias, nos noticiários de televisão e nas conversas mais informais, expressões que atribuem "nervosismo ao mercado" ou "sumiço dos postos de trabalho". O homem contemporâneo tem também suas "potências superiores", contra as quais se defronta diariamente, organizações na estrutura socioeconômica a que se atribuem condições de agir. É uma estrutura inalcançável ao indivíduo e que se objetiva na riqueza de uns poucos em detrimento da miséria de uma grande maioria. Riqueza muitas vezes ameada sobre o sangue, a dor e as lágrimas de terceiros. Essa é, em outros termos, a descoberta que o retirante Severino faz ao ouvir a fala dos dois coveiros. Os dois trabalhadores de cemitério versam sobre as desigualdades que acompanham na morte, na distribuição espacial das covas, das diferenças entre os enterros, na riqueza 
ou na pobreza, na constância:

Não creio que te mandassem

para as belas avenidas

onde estão os endereços

e o bairro da gente fina:

isto é, para o bairro dos usineiros,

dos políticos, dos banqueiros,

e no tempo antigo, dos banguezeiros

(hoje estes se enterram em carneiros)

bairro também dos industriais,

dos membros das associações patronais

e dos que foram mais horizontais

nas profissões liberais.

(MELO NETO, 1983, p. 94-95)

As avenidas dos "bairros" da "gente fina" são de belas avenidas, como em vida.

- Também um bairro dessa gente temos no de Casa Amarela: cada um em seu escaninho, cada um em sua gaveta, com o nome aberto na lousa quase sempre em letras pretas.

Raras as letras douradas, raras também as gorjetas. (MELO NETO, 1983, p. 95)

O bairro dos funcionários é descrito com a ironia da condição pequeno-burguesa, cuja aspiração em vida (e em morte) é a de ser dos bairros de "gente fina". Os funcionários, comerciários e bancários aspiram à elevação social mantendo sempre a perspectiva de superação da própria condição social e manutenção do status quo. 
- É, deixo o subúrbio dos indigentes

onde se enterra toda essa gente

que o rio afoga na preamar

e sufoca na baixa-mar.

- É a gente sem instituto, gente de braços devolutos;

são os que jamais usam luto

e se enterram sem salvo-conduto.

- É a gente dos enterros gratuitos

e dos defuntos ininterruptos.

(MELO NETO, 1983, p. 96-97)

A voz dos coveiros descreve - com pinceladas de ironia - a divisão econômica da sociedade brasileira. Ao nomear a base da pirâmide econômica como composta por severinos, o autor já afirmava em alguma medida essa condição de "indigência" prescrita pelo coveiro. Embora se apresente como personagem individual, o retirante Severino é uma alegoria para essa "gente dos enterros gratuitos e dos defuntos ininterruptos". A "potência do além", inalcançável às forças do retirante, é a estrutura socioeconômica opressora, que limita seu desejo de vida, imputando-lhe a morte como única saída para sua condição. Segundo Shelling (18561861):

O essencial da tragédia é [...] um conflito real entre a liberdade no sujeito e a necessidade, como necessidade objetiva. Esse conflito não termina com a derrota de uma ou de outra, mas pelo fato de ambas aparecerem indiferentemente como vencedoras e vencidas. (SHELLING, 1856-61, parte I, vol. 5, p. 693 apud SZONDI, 2004, p. 31. Com grifo e supressão de texto no original)

Essa leitura traz mais um dado à reflexão: o embate travado em sede trágica é irreconciliável. É um conflito que não pode ser desalinhavado 
pela simples vontade do indivíduo envolvido. Em seus Cursos de Estética, Hegel sintetiza assim sua visão sobre o trágico grego:

O trágico originário consiste no fato de que no interior de tal colisão ambos os lados da oposição, tomados por si mesmos, possuem legitimidade, ao passo que, por outro lado eles são capazes de impor o Conteúdo verdadeiro positivo de sua finalidade e caráter apenas como negação e violação da outra potência igualmente legitimada e, por isso, por sua eticidade e por meio da mesma, caem igualmente em culpa. (HEGEL, 2002, p. 237. Grifos no original)

O resultado do embate irreconciliável de forças é o sofrimento trágico do herói, dilacerado pela oposição fundamental. Conforme já apontei no início deste artigo, o título da obra de João Cabral dá pistas de uma oposição que marca seu conteúdo: morte versus vida. A viagem do retirante Severino a caminho do Recife é caracterizada como uma tentativa de superação da condição de miserabilidade severina, representada no início pela ordem social opressora das sesmarias e do coronelismo: “- E agora o que passará,/ irmãos das almas,/ o que é que acontecerá/ contra a espingarda?/ - Mais campo tem para soltar,/ irmão das almas,/ tem mais onde fazer voar/ as filhas-bala (MELO NETO,1999, p. 74-75). É pelo desejo de superação dessa condição que o retirante se lança à capital:

- Nunca esperei muita coisa, digo a Vossas Senhorias.

$\mathrm{O}$ que me fez retirar não foi a grande cobiça; o que apenas busquei foi defender minha vida de tal velhice que chega antes de se inteirar trinta; se na serra vivi vinte, 
se alcancei lá tal medida,

o que pensei, retirando,

foi estendê-la um pouco ainda.

Mas não senti diferença entre o Agreste e a Caatinga, e entre a Caatinga e aqui a Mata

a diferença é a mais mínima

(MELO NETO,1999, p. 91)

E lá chegando, pelo discurso dos coveiros, pela voz de outrem, descobre que a condição severina não pode ser deixada para trás, não pertence à localização física, de onde se encontra o retirante. Ser "severino" é uma condição social a que tantos e tantos "Severinos" estão subjugados pela distribuição desigual das riquezas, pela hierarquização social marcada por uns poucos no topo e muitos espoliados na base da pirâmide socioeconômica.

\section{Conclusão}

Espero ter demonstrado que João Cabral de Melo Neto, ao estabelecer diálogo estético com a memória social sobre a experiência grega trágica, atualiza sua forma e seus sentidos apontando questionamentos relevantes para nosso tempo. Embora a tragédia tenha surgido em condições específicas e historicamente localizadas, há uma tradição estética na qual é possível retomar seus valores específicos com base em condições econômicas e históricas novas. Nesse sentido, evidencia-se a dimensão trágica possível na contemporaneidade com a obra de João Cabral de Melo Neto.

\section{Referências}

ALMEIDA, José Américo. A poesia está presente (discurso de recepção). 
Disponível em: http://www.academia.org.br/academicos/joao-cabral-demelo-neto/discurso-de-recepcao, Acesso em: 10/09/2019

BAKTHIN, Mikhail. Problemas da poética de Dostoiévski. Tradução. Paulo Bezerra. Rio de Janeiro: Forense Universitária, 2008. . Teoria do Romance I: a estilística. Tradução. Paulo Bezerra. São Paulo: 34, 2015.

BORBA FILHO, Hermilo. Espetáculos populares do Nordeste. Recife: Massangana, 2007.

HEGEL, G.W.F. Cursos de Estética vol. IV. Tradução. Marco Aurélio Werle. São Paulo: EdUSP, 2004. (Col. Clássicos, 26)

MELO NETO, João Cabral. Morte e vida severina e outros poemas em voz alta. Rio de Janeiro: Livraria José Olympio Editora, 1983.

MEMÓRIA GLOBO. Morte e Vida Severina: O especial, vencedor do Emmy Internacional de 1982, narra a trajetória de um homem que migrou da caatinga para a cidade, Disponível em: http://memoriaglobo.globo. com/programas/entretenimento/especiais/morte-e-vida-severina/morte-evida-severina-ficha-tecnica.htm, Acessado em: 10/ 09/ 2019.

NUNES, Benedito. João Cabral: a máquina do poema. Org. Adalberto Muller. Brasília: Editora Universidade de Brasília, 2007.

SMITH, Adam. A riqueza das nações: investigação sobre sua natureza e suas causas. Tradução Luiz João Baraúna. São Paulo: Nova Cultural, 1996.

SZONDI, Peter. Ensaio sobre o trágico. Tradução Pedro Sussekind. Rio de Janeiro: Jorge Zahar, 2004.

TEATRO TUCA. Morte e Vida Severina, Disponível em: http://www. teatrotuca.com.br/50anos/morte-e-vida-severina.html, Acessado em: 10/ $09 / 2019$. 
VERNANT, Jean-Pierre; VIDAL-NAQUET, Pierre. Mito e tragédia na Grécia antiga. São Paulo: Perspectiva, 2008.

Recebido em: 24/10/2019

Aprovado em: 09/06/2020 